\title{
Breves indicacõos para o ensino de teoria sociológica hoje
}

ÉLIDA RUBINI LIEDKE*

Introdução: em que consiste a teoria sociológica?

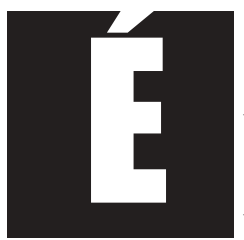

sabido que entender uma teoria implica em situar o pensamento de seu autor (ou de seus autores) em termos de tempo e lugar. Envolve apreender os motivos pelos quais estão sendo problematizados determinados modos de entendimento do mundo. Implica em fazer uma análise sociológica da teoria social. A inserção de uma obra em seu tempo e lugar não significa, porém, necessariamente, desconsiderar a dimensão referente à relativa autonomia do trabalho intelectual (Löwy, 1987). Ao contrário, fazse necessário contemplar a relação dialética entre interpretação e realidade, entre sujeito e objeto do conhecimento. Conforme Giddens (1978), a dupla hermenêutica significa que "a sociologia trata de um universo que já está constituído pelos próprios atores sociais dentro de quadros de significância e o reinterpreta dentro de seus próprios esquemas teóricos" (Giddens, 1978: 171). Ou ainda, nos termos desse mesmo autor: "O COnhecimento sociológico espirala dentro e fora do universo da vida social, reconstituindo tanto este universo como a si mesmo" (Giddens, 1990, p.

\footnotetext{
* Possui graduação em Ciências Sociais pela Universidade Federal do Rio Grande do Sul (1972), mestrado em Sociologia pela Universidade de Brasília (1977) e doutorado em Sociologia pela Brown University (1987). Atualmente é funcionária da Universidade Federal do Rio Grande do Sul. Tem experiência na área de Sociologia, com ênfase em Sociologia do Trabalho. Brasil.
} 
24). Os atores sociais, ao se apropriarem dos conhecimentos produzidos pela sociologia, atribuem-Ihes novos significados e, ao mesmo tempo, desafiam a sociologia a alcançar novos avanços.

II. A teoria sociológica busca a generalização, o que envolve argumentação discursiva, interpretação e persuasão (Alexander, 1995). O confronto entre teorias expressa modos diversos de construção do objeto, de indagação acerca de uma mesma temática. Estas visões podem vir a ser complementares ou excludentes; não há, porém, como construir um consenso unitário acerca de diferentes visões do objeto em Ciências Sociais.

III. Também segundo Alexander (1995), as teorias podem ser classificadas em especiais, que abordam temas específicos como trabalho, família, administração empresarial, e em teorias gerais, que abordam temas mais abstratos como interação social, modernidade, estrutura social, ação, coesão (bases do consenso e da coerção). O autor chama atenção para o fato de que, em teoria social, existem diferentes níveis de abstração, variando desde o âmbito empírico-descritivo de determinados temas de pesquisa até patamares de cunho teórico-explicativo que permitem alcançar generalizações acerca da problemática inicialmente formulada. Coloca-se assim o desafio de estabelecer um ponto de equilíbrio entre os dois pólos: o mais descritivo, em que se arrisca perder capacidade de generalização, mantendo o foco no detalhamento das observações empíricas, e o mais abstrato, cujos riscos referem-se a perdas quanto às especificidades temáticas.

\section{Referências para a análise das teorias}

I. As teorias auxiliam a estruturar o pensamento sobre a realidade dão-lhe significado, dão sentido aos dados coletados em uma pesquisa. Até recentemente, as teorias se localizavam em tradições científicas cujos pressupostos quanto à constituição da sociedade (o que é sociedade, como se 
dá a articulação entre indivíduo e sociedade, como se relacionam sujeito e objeto do conhecimento em ciências sociais) se expressavam de um modo bastante definido através de abordagens que enfatizavam os níveis macrossocietário - em que se assume que a sociedade afeta os indivíduos, embora reconhecendo que esses possuem a capacidade de alterar, em parte, os padrões comportamentais - e microssocietário, em que o enfoque se coloca no plano da subjetividade, do modo como os indivíduos interpretam e criam seu mundo social. Estas questões, hoje, necessitam ser analisadas sob uma nova ótica, se for considerado, como afirma Giddens (1989) que, na Sociologia, não se constitui propriamente uma relação entre sujeito e objeto, mas sim, entre sujeito e sujeito; a Sociologia precisa construir esquemas interpretativos através de descrições mediadas, traduzidas no discurso científico-social.

II. A análise do conteúdo de determinada teoria sociológica requer a identificação dos principais pontos sobre os quais recaem seus argumentos, para o que são destacados a seguir cinco aspectos ou variáveis: (1) variáveis culturais - princípios valorativos, comportamentais individuais ou grupais (note-se em Parsons, por exemplo, a relevância dos cinco pares de variáveis-padrão para avaliar o grau de modernização em um determinado sistema social; em Merton, são relevantes os padrões de comportamento adaptativo - variando do conformismo à rebeldia - prevalecentes em dada comunidade como, por exemplo, uma escola, ou uma empresa); (2) variáveis de ordem psicos-social, - intencionalidade da ação face à impossibilidade de controle, pelos indivíduos, de todas as conseqüências da sua ação, conforme apontado por Giddens, 1989; processo de construção da identidade do "eu" na relação entre ego e alter, conforme as acepções de Schutz, 1979 e de Strauss 1969, entre outros; (3) variáveis de natureza psicanalítica - constituição das estruturas psíquicas a partir da relação entre ego, id e superego; entre consciente, pré-consciente e inconsciente, nos processos 
de desenvolvimento do indivíduo e nas correspondentes homologias formuladas acerca do processo civilizatório (por exemplo, estudos sobre a personalidade autoritária, conduzidos por Adorno e Horkheimer - problemas da repressão de sentimentos, do surgimento do comportamento agressivo associado ao medo e da transferência da ansiedade a "bodes expiatórios"; também em Habermas, na TAC, detecta-se a ampliação dos problemas relativos à competência comunicativa do âmbito individual para a análise do patamar civilizatório); (4) variáveis econômicas e políticas Estados, produção e mercados (é o caso da abordagem estrutural-histórica, de Theda Skocpol, acerca das relações entre Estados, classes sociais e a questão agrária nas revoluções e (5) relações de poder - modos de exercer dominação; poder de repressão sobre o outro e sobre si mesmo; formas como ocorrem as práticas de pressão política e o uso de meios de violência física ou simbólica (como, por exemplo, a teoria de Bourdieu, centrada nos problemas relativos às disputas de poder no espaço social, bem como as abordagens inspiradas na obra de Foucault, centradas nas relações entre conhecimento e poder).

III. Prosseguindo nesta linha de construção de referências para a análise de uma abordagem teórica, propõe-se, em adendo à descrição dos aspectos anteriormente referidos, a apreensão do modo como se formulam a problemática e também os horizontes de perspectivas quanto aos avanços do conhecimento que uma dada narrativa sociológica propicia. Três linhas gerais, conforme segue, podem auxiliar na realização desta tarefa.

1. Uma primeira linha de análise refere-se à dimensão ideológicopolítica - as narrativas podem ser conservadoras (no sentido de Gouldner, 1979), liberais (enfoque nas relações inter-individuais) ou radicais (revolucionárias, romântico-proféticas ou críticas); estas últimas, referentes a correntes de pensamento subordinadas, podem tornar-se, não excepcionalmente, conservadoras ou liberais, ao assumirem posição de comando e direção de amplas camadas intelectuais (Mannheim, 1950). 
Assim, também, correntes de pensamento liberal podem ser apropriadas pelo pensamento conservador, e este, por sua vez, pode dar origem a questões que passam a ser apropriadas pelo pensamento radical, assumindo novos significados - é o caso, por exemplo, das liberdades democráticas burguesas, durante muito tempo rejeitadas pela esquerda como bandeiras conservadoras e, hoje, em boa parte revalorizadas mediante o reconhecimento dos efeitos destrutivos de todo tipo de totalitarismo. Encontra-se em Giddens (1996) a proposta de buscar uma terceira alternativa (nem esquerda nem direita, mas "terceira via") para enfrentar as distorções forjadas nos âmbitos do socialismo e do neoconservadorismo. Entende-se, porém, no presente artigo, que essa alternativa é insuficiente face às demandas urgentes que se colocam neste início de século. Aprofundam-se, no âmbito global, as desigualdades sociais, o individualismo, o uso da violência com o apoio de tecnologias complexas ante o colapso do socialismo e do Estado de Bem Estar Social como horizontes de perspectivas de uma sociedade boa e justa. Diante deste quadro, faz-se necessário assumir, como parte relevante da agenda das ciências sociais, a tarefa de apontar, mais precisamente, e a partir de uma tomada de posição crítica, de que recursos conceituais a teoria social dispõe para fazer frente a esses problemas.

2. Uma segunda linha geral de análise diz respeito à forma de construção de modelos interpretativos - refere-se à elaboração das linhas de argumentação de uma determinada abordagem teórica, suas conexões de sentido. Exemplos são o modelo sistêmico-funcional fundamentado na autopoiese, proposto por Luhmann; a teoria estrutural-histórico comparativa, de Barrington Moore Jr., Tilly e Skocpol, entre outros autores; as teorias da pós-modernidade, adotadas por Jameson, Harvey, Boaventura de Sousa Santos; a teoria da sociedade em rede, proposta por Manuel Castells; a teoria da estruturação, proposta por Giddens (1989), na qual se contrapõem dialeticamente agência e estrutura; a teoria da ação comunicativa, de 
Habermas, centrada nos conceitos de sistema e mundo da vida; a teoria das formas de poder simbólico, elaborada por Bourdieu, baseada em conceitos como os de capital, poder e violência simbólicos. Entre muitas outras narrativas, cumpriria ainda aqui referir a teoria feminista, cujas contribuições para diversas abordagens em teoria sociológica abrangem as questões interculturais investigadas a partir das relações entre sexualidade, subjetividade e identidade social, em grande parte até há pouco negligenciadas e mesmo rejeitadas à luz de discursos androcêntricos (Prá, 1999)

3. O terceiro critério de análise diz respeito à abordagem metodológica. Este se refere à abordagem da pesquisa histórico-descritiva ou empírica, ao modo como se constrói o projeto de investigação propriamente dito. Habermas, por exemplo, afirma que a teoria sociológica é falível e que a prática transformadora (revolucionária) é incerta (haja vista a desfiguração do conteúdo emancipatório do marxismo soviético a partir do socialismo burocrático, assim como as tentativas frustradas, na visão do autor, de reabilitação do conceito antropológico de trabalho não alienado. Desde esta perspectiva, os enunciados da teoria tornam-se hipotéticos (Habermas, 1994). Contrariamente a essa visão, neste artigo argumenta-se que (a) é tarefa das ciências sociais construir a articulação entre teoria e praxis. Mais ainda. visto não haver, de acordo com Giddens (1989), como controlar integralmente os efeitos da ação intencional, efetivada em planos e programas políticos e sociais - o autor refere-se aos problemas das conseqüências imprevistas da ação - e que a reflexividade refere-se a assumir responsabilidades em condições de risco, de insegurança acerca dos resultados da ciência, argumenta-se também que (b) se faz necessário incluir na agenda das ciências sociais os problemas das tomadas de decisão com base em mecanismos da democracia, com vistas à minimização dos custos sociais das ameaças ambientais globais, do fim do Estado de Bem Estar e do retorno ao assim chamado Estado de Guerra (conforme aponta Ritzer ,2001, com base em 
artigo de Castells, de 1986, em que este último, refazendo as formulações de Spencer, afirma que estaríamos enfrentando, na "sociedade conectada por cabos" - mais tarde, nos anos 90, por ele denominada sociedade informacional - um retrocesso do Estado Industrial ao Estado de Guerra).

Voltando o enfoque ao âmbito mais estrito do desenho e das técnicas de investigação, considera-se, do mesmo modo que Alexander (1995), que embora haja quem sustente que a opção por técnicas quantitativas ou qualitativas (ou então, estudos de tipo surveyversus estudos de caso) estabelece compromissos com determinadas ideologias e modelos analíticos, são os compromissos ideológicos e os modelos analíticos adotados que propiciam, favorecem ora a adoção de técnicas quantitativas, ora a de técnicas qualitativas, o que não impede, e até mesmo pode incentivar, o uso simultâneo de ambas as técnicas de investigação empírica.

\section{Propostas para o ensino de teoria sociológica}

I. A teoria sociológica abrange uma ampla gama de narrativas. Se forem consideradas a sociologia clássica e a sua diferenciação inicial, para fins didáticos demarcada em um período que se estende de 1830 a 1968, estarse-á diante de uma série diversificada de narrativas que se desdobram a partir da bifurcação entre as abordagens micro versus macro acerca das relações entre indivíduo e sociedade, ilustradas seletivamente no Diagrama 1.

A partir de 1968, a idéia de uma "explosão" de narrativas expressa a contínua produção de abordagens em teoria sociológica, de cujas principais manifestações o Diagrama 2 se propõe a apresentar. 
Sociologias, Porto Alegre, ano 9, no 17, jan./jun. 2007, p. 266-278

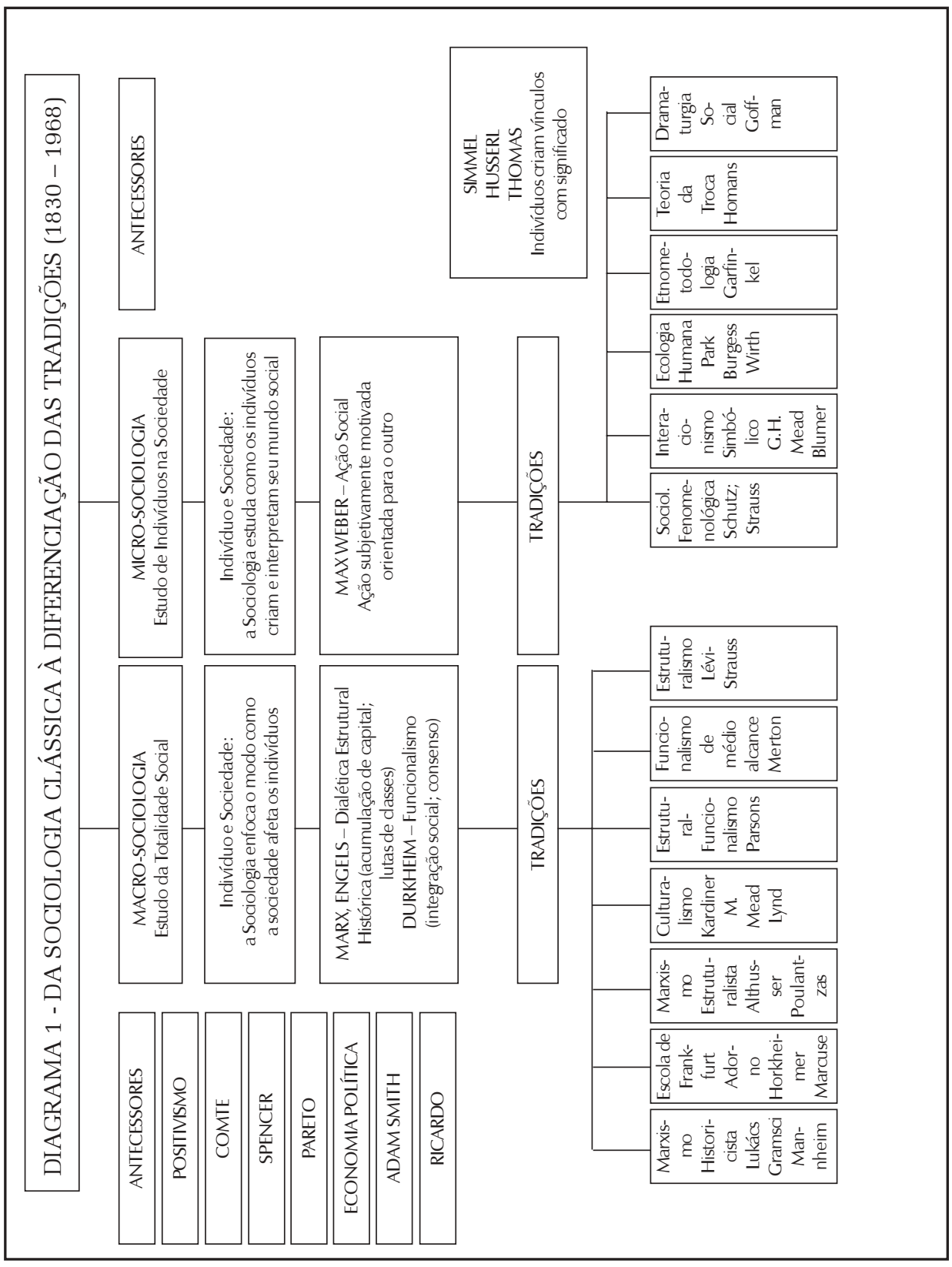




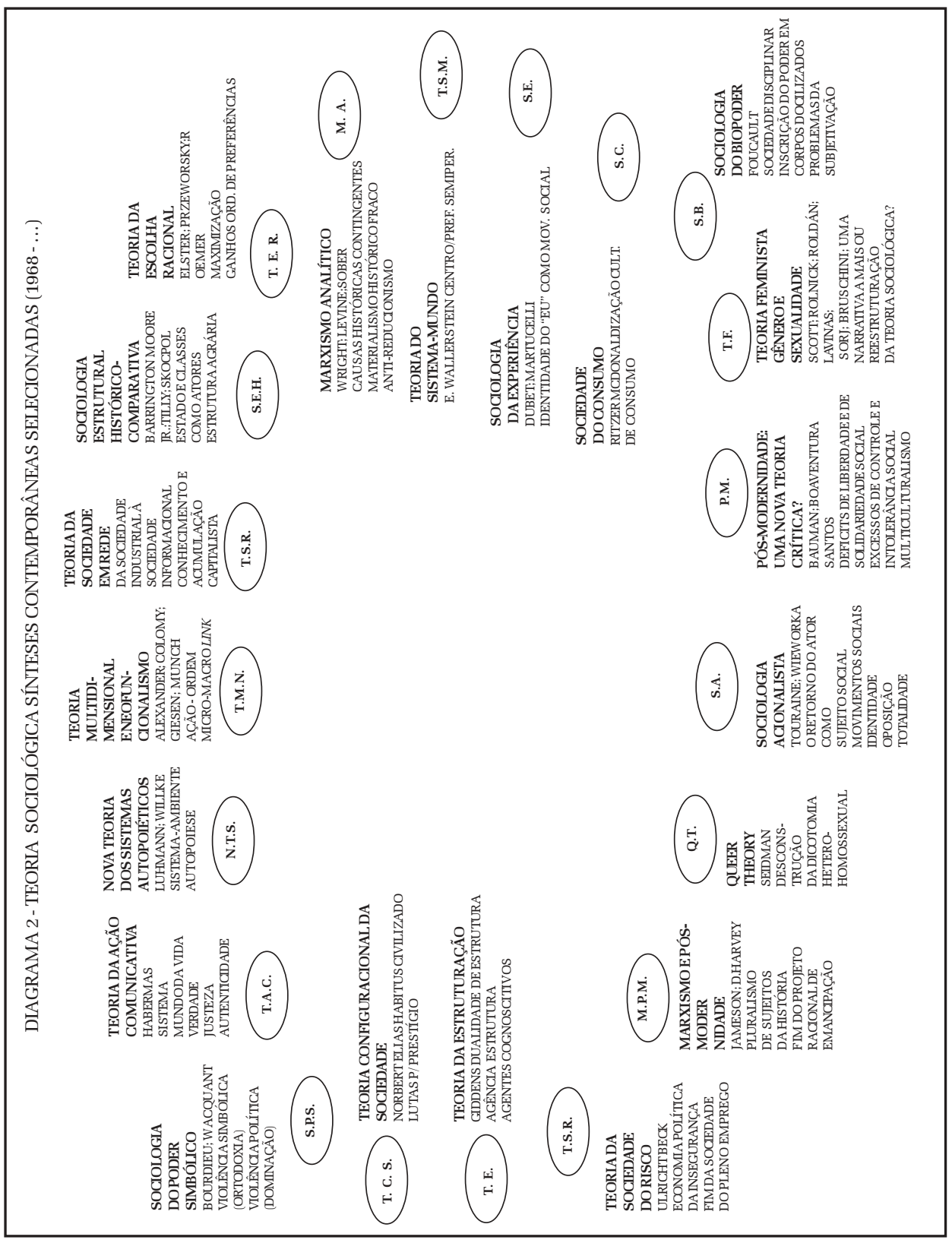


A justificação intelectual, moral e prático-política de cada abordagem teórica acarreta tensões e dilemas que demandam a continuidade do debate em fóruns democráticos. Tendo presente o movimento constante de elaboração e crítica da teoria social, apresentam-se, em linhas gerais, cinco propostas ao ensino de teoria em ciências sociais:

1. a releitura dos clássicos à luz dos problemas atuais, colocados na sociedade globalizada (Comte, Marx, Pareto, Durkheim, Weber e Parsons);

2. o aprofundamento do estudo dos processos de construção e afirmação de indentidades à luz das contribuições formuladas pelo interacionismo simbólico e a etnometodologia ( Schutz, Mead, Garfinkel, Geertz, Hughes);

3. o debate das sínteses mais recentemente produzidas com vistas a responder aos problemas relativos à conexão entre objetividade e subjetividade, ação e sistema, indivíduo e sociedade (Manuel Castells, Bauman, Touraine, Dubet, Martucelli, Giddens, Luhmann, Habermas, Sousa, Bourdieu, Foucault, entre tantos outros, são autores a serem contemplados nos programas de estudo);

4. a inclusão, nos debates, de estudos e pesquisas realizados por intelectuais brasileiros, como os de Freitag, Figueiredo, Souza, Reis, Rouanet, Domingues, dentre outros e, em especial, os estudos produzidos no âmbito do GT de Teoria Sociológica da ANPOCS; e

5. a crescente incorporação dos temas-problema acerca das relações de sexualidade e de gênero, cujas contribuições, particularmente a partir dos estudos feministas realizados nas décadas finais do século XX, transformaram radicalmente as perspectivas narrativas da Sociologia (Scott, Roldán, Sorj, Bruschini, Lavinas, entre outras).

II. Para finalizar, como roteiro simplificado de abordagem pedagógica e com vistas à análise comparativa das diversas narrativas teóricas, quatro questões são propostas: 
1. Existe um ator sujeito da história social? Caso positivo, quem é e como se constrói, historicamente, sua capacidade de ação ? Qual o seu grau de autonomia para agir? Caso negativo, como se coordenam os problemas da ordem e da tranformação social?

2. Como se estruturam as divisões sociais e de que modo elas se expressam em relações de poder?

3. Qual a visão das relações entre passado, presente e futuro, que se coloca no horizonte de uma dada abordagem teórica? e

4. Que perspectivas de aplicação em pesquisa social podem ser vislumbradas em cada uma das narrativas sociológicas enfocadas no decorrer de um determinado programa de estudos?

\section{Referências}

ALEXANDER, Jeffrey. "Que es la teoría?", In: Las teorías sociológicas desde la segunda guerra mundial. Análisis multidimensional. Barcelona: Gedisa, S. A, 1995.

BECK, Ulrich; GIDDENS, Anthony e LASH Scott. Modernização reflexiva. São Paulo: UNESP, 1997.

CASTELLS, Manuel. "Mudança tecnológica, reestruturação econômica e a nova divisão espacial do trabalho". In: Revista Espaço e debates no. 17, ano VI, 1986.

GIDDENS, Anthony. Novas regras do método sociológico. Rio de janeiro: Zahar Editores, 1978.

. A constituição da sociedade. São Paulo: Martins Fontes, 1989.

. As conseqüências da modernidade. São Paulo: UNESP, 1991.

. Para além da esquerda e da direita. São Paulo: UNESP, 1996.

GOULDNER, Alvin. "Romanticismo y clasicismo: estructuras profundas de la ciência social", In: La sociologia actual: renovación y crítica. Madrid: Alianza Editorial, 1979. 
HABERMAS, Jurgen. Teoría de la acción comunicativa: complementos y estudios previos. Ediciones Cátedra: Madrid, 1994

HEILBORN, Maria Luiza e SORJ, Bila "Estudos de gênero no Brasil", In: MICELI, Sergio (org.) O que ler na ciência social brasileira (1970-1995). Sociologia. Volume 2.São Paulo: Ed. Sumaré/ANPOCS; Brasília, Df: CAPES, 1999.

LALLEMENT, Michel. Histoire des idées sociologiques. Paris: Nathan, 1993.

LEVINE, Donald. Visões da tradição sociológica. Rio de Janeiro: Jorge Zahar Editor, 1997.

LÖWY, Michael. As aventuras de Karl Marx contra o Barão de Münchhausen. São Paulo: Busca vida, 1987.

MANNHEIM, Karl. Ideologia e utopia. Rio de Janeiro, Porto Alegre, São Paulo: Editora Globo,1950.

MOUZELIS, Nicos. Sociological theory: what went wrong? Londres e Nova York: Routledge, 1995.

PRÁ, Jussara Reis. "Antigos problemas e novos desafios: repensando a dimensão política da ação coletiva na ótica de gênero", In: BAQUERO, Marcello (org.), Desafios da democratização na América Latina: debates sobre cultura política. Porto Alegre: Editora da UFRGS/Centro Uiversitário La Salle, 1999.

RITZER, George. Teoria sociológica clásica. Madrid: McGraw Hill, 2001.

SCHUTZ, Alfred. Fenomenologia e relações sociais. Rio de Janeiro: Zahar Editores, 1979.

SOCIOLOGY AT HEWET. Map of sociological theory. Disponível em http:// www.hewett.norfolk.sch.uk/curric/soc/Theory.htm em 24/05/2004.

STRAUSS, Anselm. MEAD, George Herbert. On Social Psichology. Chicago: The University of Chicago Press, 1969.

WAGNER, Helmut R.. "A obra de Alfred Schutz; pontos de partida; o quadro da sociologia fenomenológica de Schutz", In: SCHUTZ, Alfred. Fenomenologia e relações sociais. Rio de Janeiro: Zahar Editores, 1979. 
Sociologias, Porto Alegre, ano 9, no 17, jan./jun. 2007, p. 266-278

\section{Resumo}

O artigo busca argumentar sinteticamente acerca da relevância dos estudos em teoria sociológica, considerada em termos de modelos interpretativos, os quais remetem às relações entre sujeito e objeto, assim como às conexões de sentido entre temas e problemas de ordem micro e macrossocietárias. Propõe-se a considerar cinco conjuntos de aspectos como forma de construção de referências para a análise das diversas abordagens teóricas, quais sejam: culturais, psicossociais, psicanalíticos, político-econômicos e de relações de poder. Ao final, o artigo apresenta dois diagramas ilustrativos das teorias sociológicas clássicas e contemporâneas, considerado o período de 1830 ao momento atual.

Palavras-chave: teoria sociológica, teorias sociológicas contemporâneas, teorias sociológicas clássicas, relações micro e macrossocietárias, modelos interpretativos, narrativas.

Recebido: 26/10/05

Aceite final: 21/12/05 


\section{ARTIGOS}

ARTICLES

\section{Brief indications for the teaching of sociological theory today}

\section{Élida Rubini Liedke}

The article seeks to present synthetic arguments for the relevance of studies on sociologic theory considered in terms of interpretive models, which point to subject-object relations as well as the meaning connections between themes and micro and macro societal problems. Five sets of aspects are proposed in order to build references for the analysis of distinct theoretical approaches, namely: cultural, psychosocial, psychoanalytical, political-economic and power-based relations. Finally, the article presents two diagrams illustrating classic and contemporary sociological theories, from 1830 to the present.

Key words: Sociological theory, Contemporary sociological theories, Classic sociological theories, Micro and macro-societal relations, Interpretive models, Narratives. 